\title{
动物营养学: 无抗时代下的精准营养与肠道城墙
}

\author{
印遇龙 1,2
}

1. 湖南师范大学生命科学学院, 湖南省动物肠道生态与健康国际科技创新合作基地, 动物营养与人体健康实验室, 长沙 410081;

2. 中国科学院亚热带农业生态研究所, 动物营养生理与代谢过程湖南省重点实验室, 长沙 410125

E-mail: yinyulong@isa.ac.cn

收稿日期：2020-08-16; 网络版发表日期：2020-09-08

动物营养学是一门具有 200 多年历史的传统学科, 它连接着化工业、医药添加剂制造业、饲料工业、畜 牧业、环境工业与食品工业. 因此, 动物营养学又是一 门综合性多学科交叉的应用科学, 是一门关乎国计民生 的大学科. 基于我国政府的环境保护政策、饲用抗生素 禁用以及非洲猪瘟肆虐、新冠疫情散发、国际原料贸 易不稳定的现状, 我国的畜牧业集约化进程进入空前提 速阶段. 随着2020年7月1日国家“禁抗令”的实施，所有 的饲料中不再添加任何抗生素类药物, 表明我国政府非 常重视人民健康和食品安全, 此举具有划时代的意义.

据预测, 到 2050 年, 全球人口将增长到 90 亿, 必须 增加 $60 \%$ 的粮食生产才能满足需求. 据估计, 集约化饲 养的猪和家禽的产量至少需要翻一番，才足以满足人 类对动物源食品日益增长的需求. 鉴于全球资源有限, 环境保护压力激增, 各个国家面临的关键挑战将是粮 食和饲料生产系统的可持续性. 通过精准营养探讨动 物营养成分需求，并进一步优化饲料配方，对缓解人 畜争粮局面具有重要的意义.

动物营养学, 已经从过去传统的农场动物的能 量、粗蛋白、钻磷的营养需要量的研究过渡到近几十 年的系统多学科认知，特别是近红外分析技术、微生 物学、基因组学、转录组学、遗传学和免疫学的交叉 研究, 更好地为动物营养学打开动物内部黑箱提供了
基础. 本专题中《影响猪饲料原料有效能值的关键化 学成分》阐述了动物饲料中精准配方技术; 《高锌控 制仔猪腹泻的作用机制探讨》对如何有效降低仔猪教 槽料中高锌问题以解决环境污染进行了研究; 《氨基 酸代谢调控猪免疫细胞命运研究进展》阐述了功能性 氨基酸对免疫营养的调控作用; 《乳酸菌对青拒品质 及草食家畜健康的影响》综述了微生态青拒对胃肠道 健康的作用; 《植物多酚对畜禽肠道健康的保护作用 研究进展》阐明了植物多酚在抗生素替代中的作用以 及在肠道健康发挥的效能. 上述所有创新方法综述和 讨论都是经过遴选的, 与经典动物营养学的既定理解 相结合. 本专题的每一篇综述提供所涵盖领域丰富的 信息, 可以应用到生产实践中, 为畜牧业带来帮助.

动物营养学, 在国内的研究力量及科研水平已经 和国际接轨, 在某些方面甚至已经处于领先水平. 我 们希望借此专题的梳理, 介绍当前动物营养学领域发 展态势和未来战略. 尽管本专题梳理的只是当前动物 营养学部分领域的研究进展和现状, 但我们希望借此 为饲料无抗时代的动物营养学优化升级抛砖引玉，提 高动物的精准营养供给, 减少粮食资源浪费, 改善动 物肠道健康和免疫功能, 提高抗病力, 以此应对未来 的“农场禁抗”、“食品无抗”的大挑战. 结合这个背景, 本专题的出版是一项及时并有价值的贡献.

引用格式: 印遇龙. 动物营养学: 无抗时代下的精准营养与肠道城墙. 中国科学: 生命科学, 2020, 50: 895-896

Yin Y. Animal nutrition: Precise nutrition and intestinal barrier wall in the era of no antibiotic (in Chinese). Sci Sin Vitae, 2020, 50: 895-896, doi: $10.1360 /$ SSV-2020-0284 


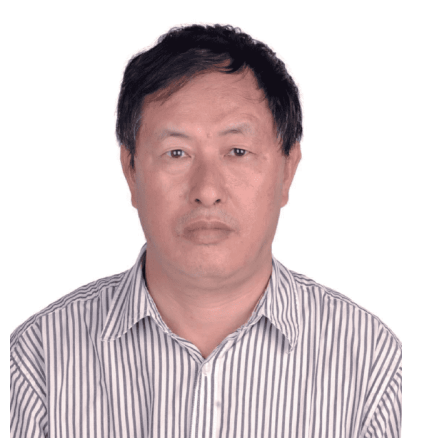

印遇龙, 1956年1月生, 湖南桃源人, 中国工程院院士, 一级研究员, 博士生和博士后 导师. NASS(新加坡南洋科学院)学部主席团主任委员. 现任中国科学院亚热带农 业生态研究所研究员. 长期从事生猪营养学研究, 在生猪健康养殖领域取得了系列 重要成果, 是国际生猪营养与健康领域最具影响力的学者之一. 中国科学院“百人 计划”学者; 以第一完成人身份获“国家科学技术进步奖”三项和“国家自然科学奖” 一项；获得2017年度“湖南省科学技术最高奖”，2019年度“何梁何利基金科学与技 术进步奖”. 带领团队在专业主流期刊发表 SCI收录论文 300 多篇, 谷歌学术H指数 73 , 总被引次数 26258 次, 自2011年以来, 汤森路透全球高被引科学家入选者. 2018 年在澳大利亚布里斯班举行的第14届国际猪消化生理学大会上获Asia-Pacific $\mathrm{Nu}-$ trition Award(APNA). 